\title{
Diabetic macular oedema: pathophysiology, management challenges and treatment resistance
}

\author{
Bobak Bahrami $^{1,2}$ • Meidong Zhu ${ }^{1,2}$ • Thomas Hong ${ }^{1}$ - Andrew Chang ${ }^{1,2}$
}

Received: 9 March 2016 / Accepted: 11 April 2016/Published online: 14 May 2016

(C) Springer-Verlag Berlin Heidelberg 2016

\begin{abstract}
Diabetic macular oedema (DMO) is the leading cause of vision loss in patients living with diabetes. DMO results from hyperglycaemia-induced activation of pathways that lead to oxidative stress and release of cytokines, impairing the inner and outer blood-retinal barriers. Improved understanding of the pathophysiological mechanisms leading to DMO have led to the development of effective therapies, including vitreoretinal surgery, laser photocoagulation, intravitreal anti-vascular endothelial growth factor drugs and corticosteroids. Advances in imaging, including fluorescein angiography and optical coherence tomography, have also enhanced diagnosis and management of the condition. Despite these advances, there remain patients who do not respond completely to therapy, reflecting the complex pathophysiology of DMO. These patients may be considered treatment-resistant. In this review, we summarise the pathophysiology of DMO, as well as the available treatments and their mechanism of action. Additionally, we focus on treatment-resistant disease and review the literature on potential options for managing this complication of diabetes.
\end{abstract}

Keywords Anti-vascular endothelial growth factor · Diabetic macular oedema $\cdot$ Intravitreal corticosteroids $\cdot$ Laser photocoagulation $\cdot$ Review $\cdot$ Treatment resistance . Vitrectomy

Andrew Chang

achang@sydneyretina.com.au

1 Sydney Institute of Vision Science, 13/187 Macquarie Street, Sydney 2000, NSW, Australia

2 Save Sight Institute, University of Sydney, Sydney, NSW, Australia

\begin{tabular}{|c|c|}
\hline \multicolumn{2}{|c|}{ Abbreviations } \\
\hline ACCORD & $\begin{array}{l}\text { Action to Control Cardiovascular Risk in } \\
\text { Diabetes }\end{array}$ \\
\hline BCVA & Best-corrected visual acuity \\
\hline BRB & Blood-retinal barrier \\
\hline CMT & Central macular thickness \\
\hline DMO & Diabetic macular oedema \\
\hline DRCR.net & $\begin{array}{l}\text { Diabetic Retinopathy Clinical Research } \\
\text { Network }\end{array}$ \\
\hline ETDRS & Early Treatment of Diabetic Retinopathy Study \\
\hline FA & Fluorescein angiography \\
\hline FAME & Fluocinolone Acetonide for Macular Edema \\
\hline ILM & Inner limiting membrane \\
\hline IOP & Intraocular pressure \\
\hline nAMD & Neovascular age-related macular degeneration \\
\hline OCT & Optical coherence tomography \\
\hline PDR & Proliferative diabetic retinopathy \\
\hline PKC & Protein kinase $\mathrm{C}$ \\
\hline PIGF & Placenta growth factor \\
\hline PVD & Posterior vitreous detachment \\
\hline RESTORE & $\begin{array}{l}\text { Ranibizumab Monotherapy or Combined with } \\
\text { Laser versus Laser Monotherapy for Diabetic } \\
\text { Macular Edema }\end{array}$ \\
\hline RPE & Retinal pigment epithelium \\
\hline VEGF & Vascular endothelial growth factor \\
\hline VMT & Vitreomacular traction \\
\hline
\end{tabular}

\section{Introduction}

Diabetic macular oedema (DMO) is a leading cause of vision loss and the most common cause of vision loss in diabetic patients, affecting an estimated 21 million people worldwide in 2010 [1, 2]. DMO typically affects adults of a working age, 
and therefore has not only direct costs to the healthcare system but indirect costs incurred by lost productivity $[1,3]$.

The prevalence of DMO varies among the diabetic population, with the condition affecting $14.3 \%$ and $5.6 \%$ of type 1 and type 2 diabetic patients, respectively. Duration of diabetes is a risk factor, with $3.2 \%$ of those living with diabetes for less than 10 years affected compared with $20.0 \%$ of those having diabetes for more than 20 years. The prevalence of DMO is also higher among those with poorer $\mathrm{HbA}_{1 \mathrm{c}}$, hypertension and serum cholesterol $>4.0 \mathrm{mmol} / 1$ [2].

The diagnosis and management of DMO was standardised by the Early Treatment of Diabetic Retinopathy Study (ETDRS) report number 1 [4]. Macular focal/grid laser photocoagulation was found to halve the rate of vision loss in DMO over 3 years. Macular laser therapy consequently remained the standard of care for DMO for over two decades.

In recent decades, the pathophysiological pathways involved in the development of DMO have been better identified. Consequently, new classes of therapies have been studied and developed in addition to macular laser therapy, initially intravitreal corticosteroids and subsequently anti-vascular endothelial growth factor (VEGF) drugs. Furthermore, imaging advances with optical coherence tomography (OCT) and fluorescein angiography (FA) have allowed for improved diagnosis, assessment of prognosis and monitoring response to therapy.

Despite these advances, there remains a proportion of patients who do not adequately respond to the current standard of care pharmacological therapeutic options. Although this phenomenon may be termed treatment-resistant DMO, there is no consensus on the definition of DMO.

Indicators commonly used to measure treatment effectiveness are duration of, number of, and response to previous treatments in conjunction with visual acuity, central macular thickness (CMT) and residual oedema presenting within or under the retina. Although clinical trial data guide the prevalence of treatment resistance with pharmacotherapy based on these criteria, these indicators have limitations. For example, there is less lost vision to be regained in a patient with a better presenting visual acuity and CMT values differ depending on the OCT machine used [5].

In the Diabetic Retinopathy Clinical Research network (DRCR.net) Protocol I study (ClinicalTrials.gov: NCT00444600), treatment success was defined as visual acuity equivalent to $20 / 20$ or a $\mathrm{CMT}<250 \mu \mathrm{m}$. Approximately $75 \%$ of patients were incomplete responders according to these criteria following four loading doses of ranibizumab at 16 weeks of follow-up. Despite additional laser therapy being given to all arms in this study, $40-50 \%$ of participants in the ranibizumab and triamcinolone arms were incomplete responders following 12 months of therapy [6].
These rates did not change significantly at 2 years of follow-up, suggesting that response is likely to be seen following 4-12 months of therapy. Similar rates of response to anti-VEGF drugs have been found in the DRCR.net Protocol T study (ClinicalTrials.gov: NCT01627249) [7]. As such, reasonable criteria for treatment resistance based on trial data would be at least four to six treatments with intravitreal pharmacotherapy with at least 6 months of follow-up and significant residual oedema visualised on OCT. Many authors have attempted to identify and treat treatment-resistant DMO. These studies, including their criteria for defining treatment resistance, are summarised in Table 1.

Treatment resistance likely reflects the complex pathophysiology of DMO. This review summarises the pathophysiology of DMO, mechanisms of action for established therapies and reviews case series and trials for the management of treatment-resistant DMO.

\section{Systematic literature search}

A systematic literature search was performed using MEDLINE (from 1966 to February 2016) and EMBASE (from 1950 to February 2016). Keywords searched included: refractory, recalcitrant, treatment-resistant, switching, pathogenesis, VEGF, risk factors, genetics, steroid, laser, vitrectomy, optical coherence tomography, fluorescein angiography and diabetic macular oedema. The reference lists of cited papers were examined to find additional articles of relevance. Only papers published in English from peer-reviewed articles and original descriptions were included and there were no restrictions applied to study type.

\section{Pathophysiology}

The pathophysiology of DMO is multifactorial and complex, involving mechanical and biochemical pathways triggered by hyperglycaemia. Better understanding of these pathways has led to the development of effective therapies, including laser photocoagulation, vitreoretinal surgery and systemic and ophthalmic pharmacotherapy.

The common pathway that leads to macular oedema in DMO as well as other exudative retinal conditions is breakdown of the blood-retinal barrier (BRB) [8]. The BRB consists of the inner BRB and the outer BRB, which exist to maintain homeostasis in the neural tissue. The inner BRB is formed by tight junctions between retinal endothelial cells, the surrounding basal lamina, pericytes, astrocytes and microglia. The outer BRB is formed by the tight junctions between retinal pigment epithelium (RPE) cells. Impaired integrity of the BRB leads to leakage of plasma solutes into the interstitial spaces, causing oedema through increased osmotic pressure. 


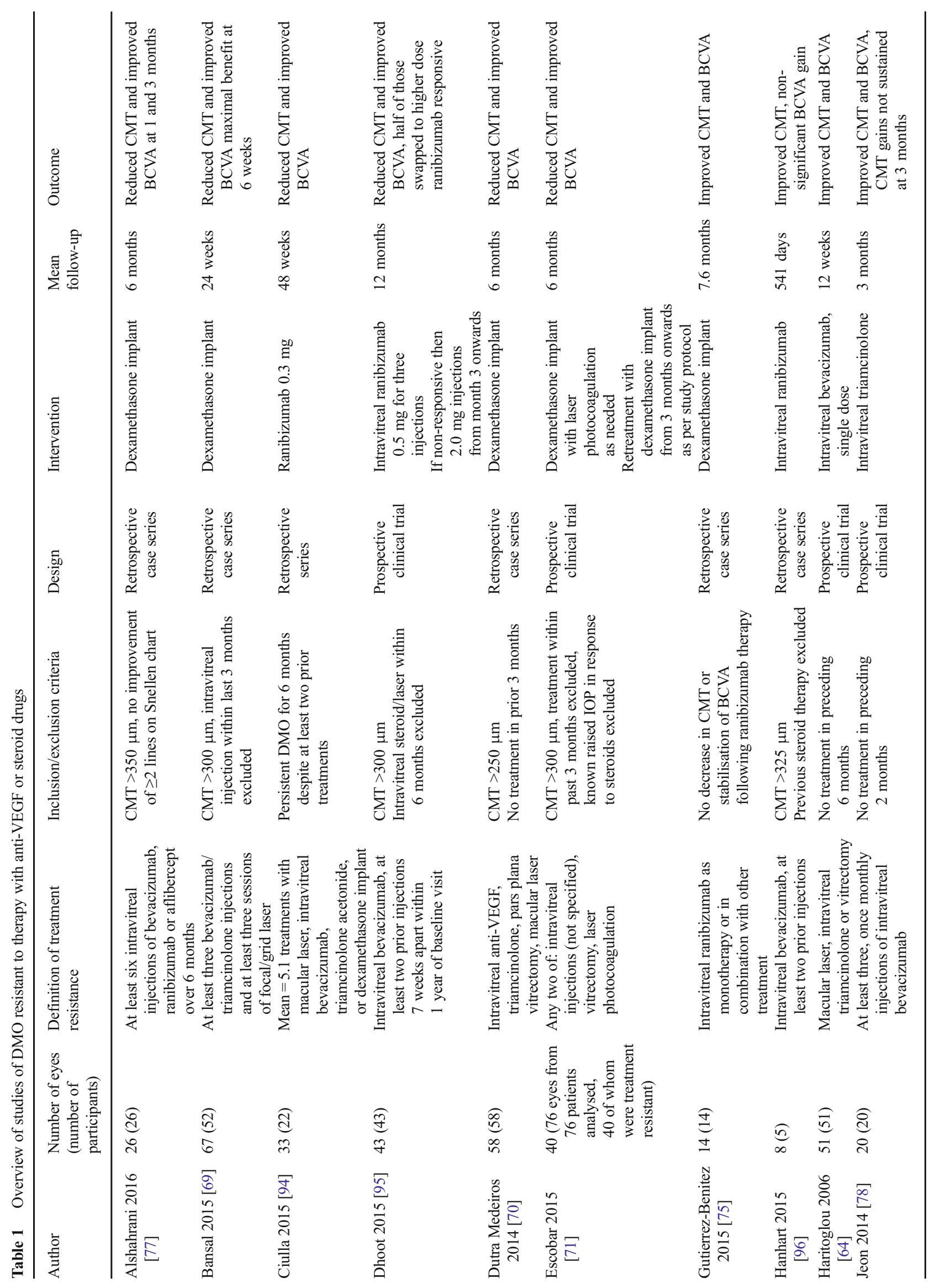




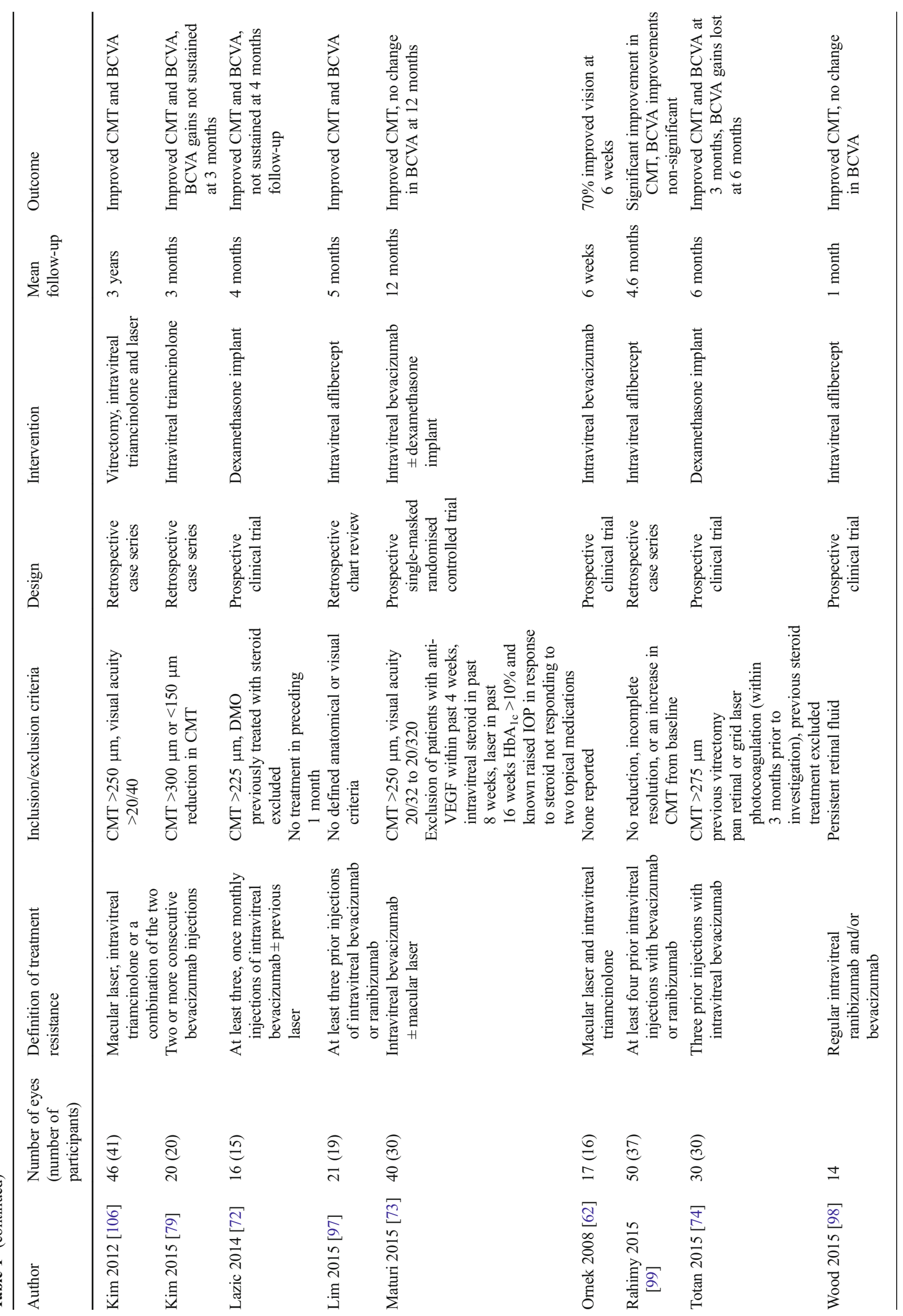




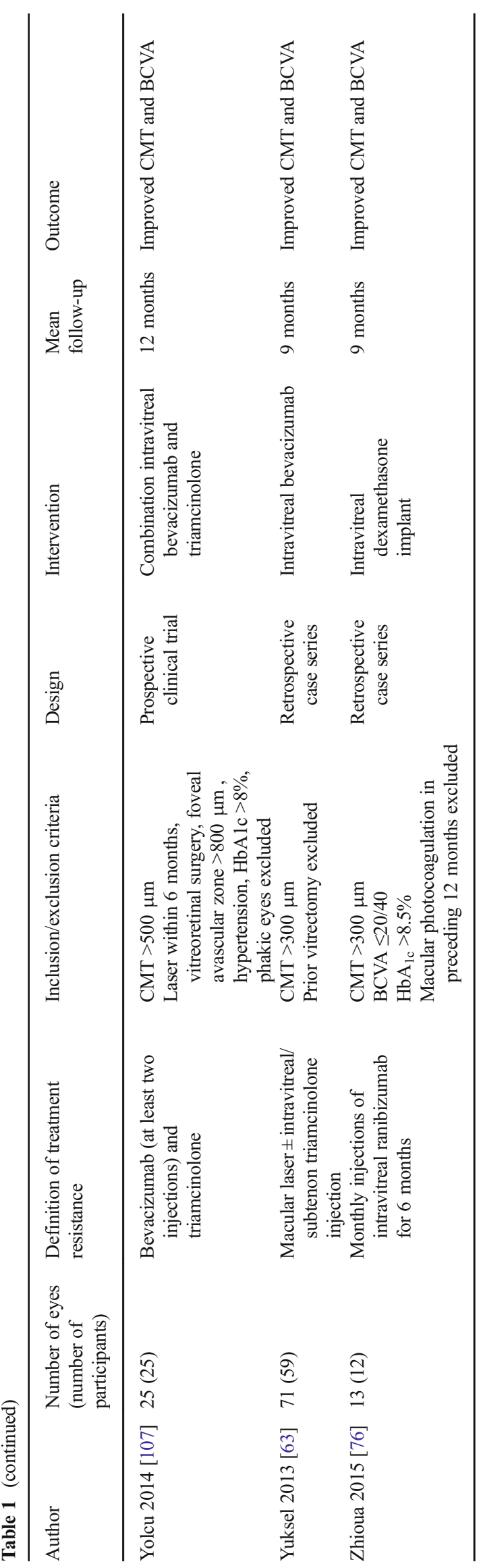


Fluid subsequently accumulates in different spaces within and underneath the retina, as shown in Fig. 1.

Disruption of the BRB in diabetic retinopathy results from the release of inflammatory cytokines and growth factors in states of chronic hyperglycaemia. Important factors implicated include VEGF-A, placenta growth factor (PIGF), IL-8, IL-6, IL- $1 \beta$, TNF- $\alpha$ and matrix metalloproteinases [8-10].

Hyperglycaemia-mediated activation of several identified biochemical pathways promotes the formation of these factors. These mechanisms include increased flux through the polyol pathway, activated protein kinase $\mathrm{C}$ (PKC) and the formation of AGEs.

Aldose reductase uses NADPH to reduce excess glucose to sorbitol in the polyol pathway. While some sorbitol is oxidised to fructose by sorbitol dehydrogenase through the use of $\mathrm{NAD}^{+}$, the majority remains unchanged. The consumption of NADPH in this pathway prevents the regeneration of glutathione and other free radical scavengers, increasing oxidative stress on the cell [11].

Diacylglycerol increases in hyperglycaemic states, and activates $\mathrm{PKC}$, the $\beta$ isoform of which is found in high concentrations in the retina [12]. Activated PKC- $\beta$ mediates retinal vascular permeability, leading to hypoxia, and upregulates VEGF signalling pathways, leading to further BRB impairment [13].

Hyperglycaemia also causes non-enzymatic glycation of plasma proteins and the basal lamina, which leads to the production of AGEs. Accumulation of AGEs in the vitreous causes cross-linking of collagen, leading to an abnormally adherent vitreoretinal interface [14]. These mechanical forces contribute to DMO. AGEs also bind to AGE receptors in Müller cells, causing upregulation of nuclear factor- $\mathrm{kB}$, which increases the transcription of inflammatory cytokines and VEGF [15]. BRB function may be affected directly by AGE-mediated alterations of transmembrane proteins, such as integrins [8].

The development of DMO is a multifactorial process. Disease refractory to a particular therapeutic approach may reflect a failure to recognise one or a combination of the pathways involved or upregulation of other growth factors, as discussed below $[9,16]$. Improved understanding of
DMO pathophysiology will lead to more effective treatment of DMO.

\section{Imaging}

The diagnosis and management of DMO is facilitated by multiple imaging techniques. Fundus FA visualises the retinal vasculature and identifies lesions of diabetic retinopathy, areas of ischaemia, demonstrated by capillary dropout, and areas of impaired BRB function, demonstrated by leakage of dye. It can help predict prognosis and response to treatment in DMO. An illustration of this is diffuse DMO, defined by fluorescein leakage involving most of the macula. This form of DMO is more difficult to treat than focal DMO involving leakage from identified lesions [17]. Another important example is the degree of capillary non-perfusion and macular ischaemia, shown by an enlarged foveal avascular zone.

With the development of ultra-widefield imaging, FA can be performed with visualisation of up to $200^{\circ}$ of the retina (Fig. 2). Extensive ischaemia in the retinal periphery has been associated with recalcitrant disease and ultra-widefield FA may help identify DMO that is likely to be treatment-resistant [18].

OCT uses light interference to produce high-resolution ultrastructural images of the macular region. These images allow cross-sectional visualisation of oedema, similar to a histological section (Fig. 1). OCT technology has developed significantly in recent years. The resolution and acquisition speed of scanning has improved from early time-domain OCT to current spectral-domain OCT (SD-OCT). SD-OCT allows for improved axial resolution and imaging of deeper structures including the choroid, which can be affected in DMO [19]. Coupled with eye tracking, newer machines allow for reliable and reproducible quantifiable measurements of the CMT. Serial imaging with OCT is critical in the management of DMO. Indeed, the ETDRS criteria for clinically significant macular oedema are becoming less relevant as OCT has established itself as the new reference standard for the diagnosis and monitoring of DMO [20].

Recognising morphological biomarkers, such as those apparent on OCT or FA, may become an important factor in

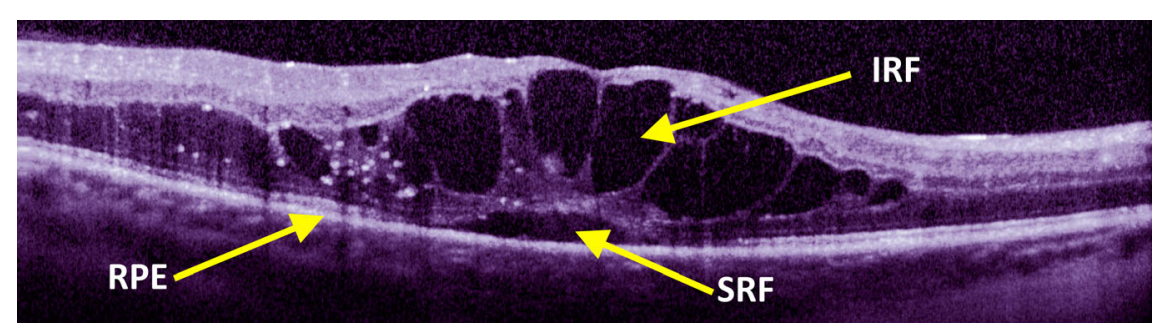

Fig. 1 OCT in a patient with DMO involving the fovea. OCT provides an ultrastructural overview of the retina similar to a histological section. Note the presence of subretinal fluid accumulating above the RPE and intraretinal fluid. IRF, intraretinal fluid; SRF, subretinal fluid 
Fig. 2 Ultra-widefield FA of a patient with severe nonproliferative diabetic retinopathy and DMO. There is significant leakage of dye into the macula (arrowhead) and areas of capillary non-perfusion corresponding to ischaemic retina (arrows). The discrete dots seen throught the image correspond to microaneurysms

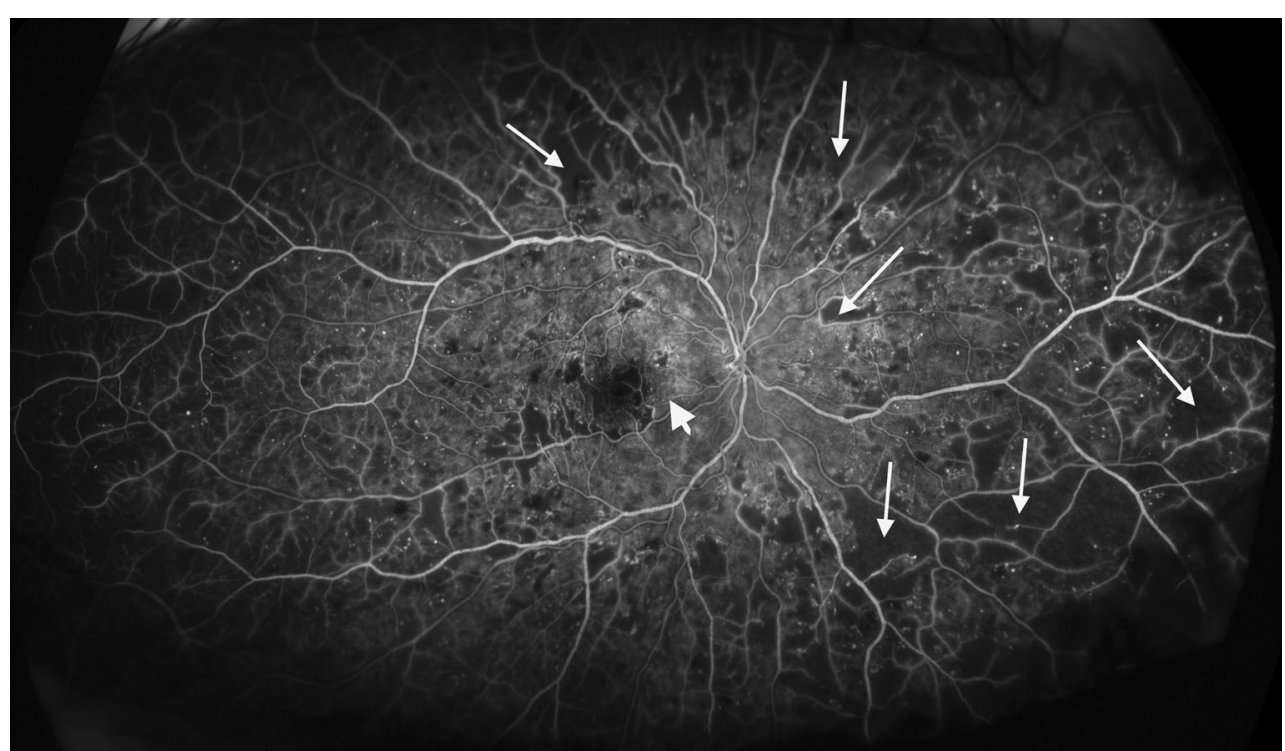

predicting which patients are likely to have recalcitrant disease, guiding individual treatment regimens [21]. Future improvements in imaging, such as OCT angiography, which non-invasively visualises retinal capillary layers, may play a role in the diagnosis, monitoring and management of DMO [22].

\section{Environmental and genetic factors}

Hypertension, established cardiovascular disease, advanced diabetic retinopathy and proliferative diabetic retinopathy (PDR) have been associated with diffuse DMO in retrospective series [23]. Despite this correlation, controlling blood glucose, blood pressure and lipid control had no benefit in modifying DMO prognosis in the prospectively designed Action to Control Cardiovascular Risk in Diabetes (ACCORD) study (ClinicalTrials.gov: NCT00000620) [24].

A recent meta-analysis of randomised clinical trials of lipid control showed no strong relationship between dyslipidaemia and DMO [25]. However, statins may have an independent effect on stabilising the BRB by reducing retinal vascular inflammation rather than by their lipid-lowering effect alone [26].

Fenofibrate, which is thought to exert its therapeutic effect on diabetic retinopathy through non-lipid biochemical pathways, has shown some promise in the management of DMO. The Fenofibrate Intervention and Event Lowering in Diabetes (FIELD) study (ISRCTN 64783481) demonstrated that participants who received fenofibrate vs placebo were less likely to require laser therapy for both PDR as well as DMO [27]. In the ACCORD Eye Study, participants who used fenofibrate had less progression of retinopathy compared with those receiving placebo, although this study demonstrated no benefit in the improvement of DMO [28]. The addition of fenofibrate and statins to the management of patients with treatment-resistant DMO may be a consideration for physicians.

Many clinical trials evaluating the treatment of DMO exclude patients with uncontrolled diabetes based on their $\mathrm{HbA}_{1 \mathrm{c}}$. This selection bias makes management of these patients especially challenging given the scant evidence to support the use of therapies. Additionally, these patients may represent a significant proportion of those with recalcitrant disease. While the role of systemic medical therapy for DMO is unclear, preventing the progression of retinopathy should be a clear goal in management strategies for all diabetic patients, especially given the association between $\mathrm{HbA}_{1 \mathrm{c}}$ and worsening retinal ischaemia [29].

There are disparities in the risk of developing diabetic retinopathy among patients of different ethnic groups, even after correction for environmental factors. These differences may be explained by a genetic predisposition to disease. Polymorphisms in the VEGF (also known as VEGFA) gene are associated with severity of retinopathy and an increased risk of development of DMO [30, 31]. Additionally, polymorphisms in the AKR1B1 gene, which encodes aldose reductase, have been associated with diabetic retinopathy development, irrespective of ethnic background [32]. Further studies examining genetic factors associated with DMO may lead to improved diagnosis and tailored treatments for this condition. These factors may also be determinants for response to treatment and therefore contribute to treatment resistance.

\section{Laser therapy}

The ETDRS demonstrated that focal/grid argon laser photocoagulation of macular lesions led to a significant reduction in 
vision loss in eyes with 'clinically significant macular oedema' [4]. This was defined as retinal thickening within $500 \mu \mathrm{m}$ of the macular centre, hard exudates within $500 \mu \mathrm{m}$ of the macular centre with adjacent retinal thickening and/or one or more disc diameters of retinal thickening, part of which is within one disc diameter of the macular centre. Figure 3 is a fundus photography illustrating an example of clinically significant DMO prior to and following ETDRS-guided laser photocoagulation.

While the rate of vision loss was halved in this study, visual improvements were modest or non-existent. Vision improvements are seen in approximately $15 \%$ of patients after 3 years of follow-up [33]. Using vision criteria, treatment resistance with macular laser therapy reaches rates of $85 \%$.

Macular laser photocoagulation improves DMO through a number of proposed mechanisms. First, photoreceptors and RPE cells are destroyed via a photothermal mechanism, thus reducing oxygen consumption. This reduced oxygen consumption in the outer retina is postulated to increase

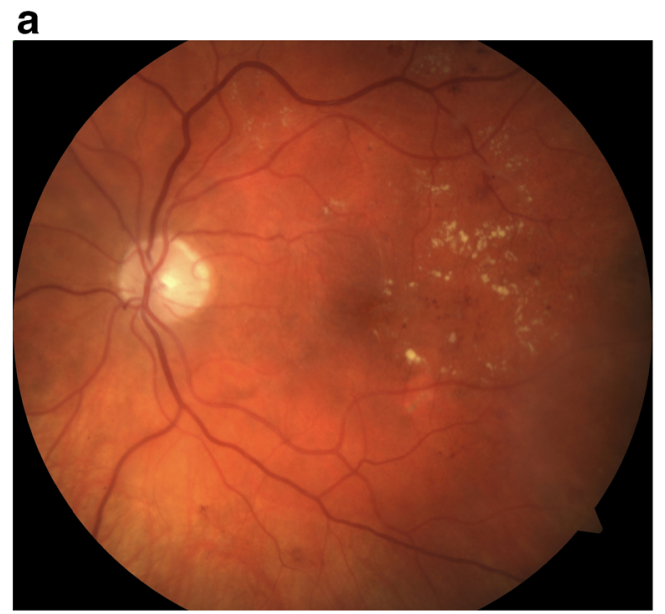

b

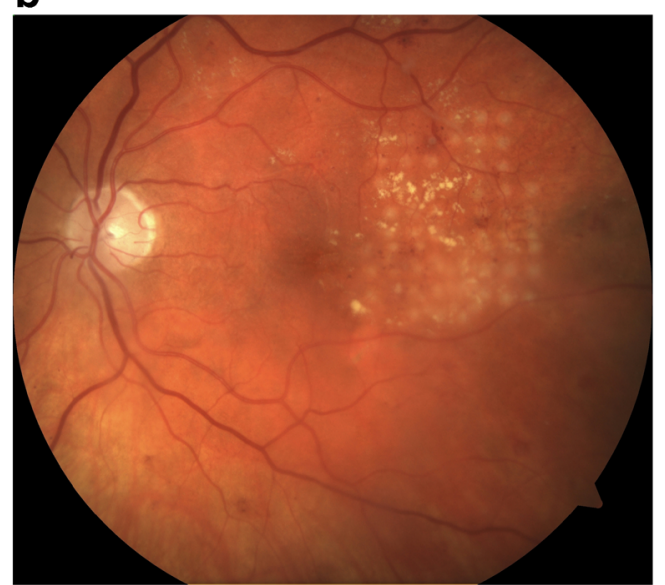

Fig. 3 Fundus photograph demonstrating clinically significant macular oedema (a) before and (b) after ETDRS-guided laser photocoagulation. Note the presence of hard exudates associated with retinal thickening within $500 \mu \mathrm{m}$ of the macular centre, as well as other changes of diabetic retinopathy including retinal haemorrhages and microaneurysms oxygen flux from the choroid to the inner retina, thus leading to arteriolar constriction and a decrease in the hydrostatic forces that drive oedema [34]. Second, photocoagulation induces changes to the RPE cells, causing their proliferation and the release of cytokines such as TGF- $\beta$, which antagonise the effects of VEGF [35]. Finally, there can be direct ablation of microaneurysms contributing to oedema, identified as leaking on FA.

Macular laser photocoagulation has the risk of causing several sight-threatening complications, including scotoma, choroidal neovascularisation and subretinal fibrosis [36]. Given these risks and the availability of anti-VEGF drugs, macular focal/grid laser therapy is now generally reserved for non-centre-involving DMO. From the 3 year results of the DRCR.net Protocol I study, use of focal/grid laser therapy may even lead to poorer long-term visual outcomes in patients with DMO when initiated at the same time as anti-VEGF therapy [37].

Recent advances in technology have led to the development of lasers with lower energies and different wavelengths, duration of pulses and pattern deliveries, which aim to target pathology directly. This aims to reduce collateral damage to the retina and surrounding structures.

Diode lasers, for example, which have a shorter pulse length, are effective in the management of DMO. A 12 month randomised controlled trial compared conventional argon laser with micropulse diode photocoagulation for the management of clinically significant DMO and found anatomical and functional outcomes to be similar [38]. The photothermal effect of these micropulse lasers is designed to be confined to the RPE, thus sparing complications associated with damage to the photoreceptor and nerve fibre layer, and loss of ganglion cells. These therapies may also be more comfortable for the patient as choroidal heating is less likely to occur. Whether micropulse laser can be effective as an adjunct to other therapies for DMO is yet to be investigated.

Future directions for laser photocoagulation include the treatment of peripheral ischaemia identified on ultrawidefield FA. These ischaemic areas have been hypothesised to drive DMO in treatment-resistant patients and laser photocoagulation may play a role in management of these individuals $[18,29]$.

\section{Surgical management}

The vitreous body is variably attached to the inner limiting membrane (ILM) of the neurosensory retina at macula. Over time, this vitreoretinal adhesion can weaken and the vitreous pulls away from the macula. If this separation is complete, it is termed a posterior vitreous detachment (PVD). If incomplete, remaining adhesions in a partial PVD can cause traction at the macula in a condition termed vitreomacular traction (VMT). 
Vitreoretinal interface abnormalities such as these may be part of the pathophysiology of DMO and related to AGEmediated pathways as previously described. DMO associated with a thickened and taut posterior vitreous face and VMT has been shown to be responsive to vitrectomy [39]. In this surgical procedure, the vitreous body is surgically removed. Vitreomacular adhesion without traction has also been associated with DMO [40]. Vitrectomy causing a PVD has been shown to improve visual and anatomical outcomes in cases of non-tractional DMO, and enzymatic PVD may play a future role in the management of treatment-resistant DMO [41]. The ILM may act as a diffusion barrier to mediators such as VEGF, and peeling this as part of vitrectomy may also improve anatomical outcomes in treatment-resistant DMO [42].

Furthermore, vitrectomy is postulated to improve DMO through increasing oxygen delivery to ischaemic areas via two mechanisms [34]. First, the vitreous is replaced by less viscous aqueous humour, which increases the diffusion capacity of oxygen as well as other molecules as per Fick's laws of diffusion. Second, fluid currents within the vitreous cavity are able to transport oxygen more efficiently from well-perfused areas to the ischaemic retina. This concept of vitreoperfusion and microplasmin-induced PVD increasing intravitreal oxygen levels has been demonstrated in animal models, supporting this theory [43].

Vitrectomy may be considered in cases refractory to treatment with repeated pharmacotherapy and especially in cases where there is vitreomacular attachment or VMT. As monotherapy, vitrectomy is insufficient to manage DMO as it fails to address the continual production of growth factors and cytokines implicated in pathogenesis. A systematic review and meta-analysis of vitrectomy in eyes without epiretinal membranes or traction showed anatomical improvement in DMO at 6 months' follow-up. However, this effect was lost at 12 months and there was a suggestion that they could lead to inferior functional outcomes compared with laser [44].

Conversely, removing the vitreous may have implications complicating the management of DMO. The half-life and intravitreal concentrations of injected intravitreal drugs are significantly reduced in vitrectomised eyes, suggesting reduced efficacy of these treatments [45]. One study has demonstrated poorer visual acuity and CMT with anti-VEGF therapy in vitrectomised eyes [46].

\section{Anti-inflammatory therapy}

Inflammation plays a key role in the pathogenesis of DMO, with increased expression of inflammatory mediators, leucocyte adhesion, complement activation, macrophage infiltration and acute phase proteins occurring in the disease state $[10,47]$. Accumulation of leucocytes coincides with vascular dysfunction, leading to breakdown of the BRB, premature cell injury and death and ischaemia [48]. Experimental data also show that by blocking leucocyte adhesion, BRB breakdown and endothelial cell injury are prevented [49].

Corticosteroids Treatment of DMO with corticosteroids reduces the vitreous levels of inflammatory cytokines and VEGF [50]. Glucocorticoids function by reducing inflammation and maintaining the BRB through increased expression of tight junction proteins [51].

Three types of corticosteroid have been evaluated for DMO in clinical trials: triamcinolone (Kenalog-40, Bristol-Myers Squibb, Princeton, NJ, USA; Triescence, Alcon, Fort Worth, TX, USA; and Trivaris, Allergan, Irvine, CA, USA); dexamethasone implant (Ozurdex, Allergan, Irvine, CA, USA); and fluocinolone acetonide implant (Retisert, Bausch + Lomb, Rochester, NY, USA; and Iluvien, Alimera Science, Alpharetta, GA, USA).

Macular laser therapy has been compared with intravitreal triamcinolone for DMO in a prospective randomised controlled trial of 84 eyes [52]. The triamcinolone group demonstrated a significant gain in vision at 2 years at the expense of increased cataract formation and elevated intraocular pressure (IOP), both common adverse events in trials evaluating intravitreal steroids [53]. Similar results have been found in other studies comparing triamcinolone with laser therapy $[54,55]$. The DRCR.net Protocol I compared ranibizumab in combination with prompt or delayed laser therapy vs triamcinolone and prompt laser therapy vs laser therapy and sham injections in a total of 854 eyes [56]. The reduction in CMT was similar in all groups, but there was no improvement in visual acuity in the triamcinolone arm compared with laser alone, which was accounted for by cataract formation. Indeed, when individuals with pseudophakia were analysed as a subgroup, the visual improvement in the triamcinolone arm was comparable with that in the ranibizumab-treated arms [56].

In a randomised controlled trial of 171 eyes, $0.35 \mathrm{mg}$ and $0.7 \mathrm{mg}$ dexamethasone implants were evaluated for DMO (ClinicalTrials.gov: NCT00035906) [57]. While there were significant reductions in CMT, the best-corrected visual acuity (BCVA) was unaffected. The Macular Edema: Assessment of Implantable Dexamethasone in Diabetes (MEAD) study (ClinicalTrials.gov: NCT01492400) subsequently demonstrated anatomical and BCVA improvement with $0.35 \mathrm{mg}$ and $0.7 \mathrm{mg}$ dexamethasone implants compared with a sham procedure in a larger study of 1,048 eyes [58]. The $0.7 \mathrm{mg}$ implant was compared head-to-head with bevacizumab in the prospective randomised controlled BEVORDEX study (ClinicalTrials.gov: NCT01298076), which found similar improvements in visual acuity but superior reduction of CMT in dexamethasone-treated eyes. Additionally, fewer treatments were required in the dexamethasone arm [59]. 
Fluocinolone implants, which contain $0.59 \mathrm{mg}$ of fluocinolone acetonide, release approximately $0.5 \mu \mathrm{g}$ of drug per day for approximately 3 years. The surgically inserted Retisert implant was compared with sham injections combined with standard of care laser therapy in a prospective randomised trial of 196 eyes (ClinicalTrials.gov: NCT00502541). While this study showed improved visual outcomes for the fluocinolone arm, there were notable complications, with surgical intervention required for cataract in $91 \%$ of phakic participants and ocular hypertension in $33.8 \%$ participants [60].

The Fluocinolone Acetonide for Macular Edema (FAME) study (ClinicalTrials.gov: NCT00344968) was a randomised trial of 953 eyes that compared 0.2 or $0.5 \mu \mathrm{g}$ /day Iluvien implants delivered via an intravitreal injection with sham injections [61]. After 24 months, eyes gained an average of 4.4 and 5.4 letters in the low- and high-dose fluocinolone groups, respectively, compared with 1.7 letters in the sham group. Additionally, this preparation had lower rates of intervention for ocular hypertension and cataract than the trial of Retisert. Currently, Iluvien is the only preparation approved for use in DMO.

Given the side effects of steroids, they are generally reserved as second-line therapy after anti-VEGF drugs. Indeed, this is why switching therapy from steroid to antiVEGF is scantly reported [62-64]. However, with the need for regular injections reduced, there can be an argument made for the use of these agents earlier in a treatment algorithm, especially in pseudophakic eyes. Caution is required, and close monitoring is needed to assess for elevated and uncontrolled IOP, which can lead to rapid visual loss.

Non-steroidal anti-inflammatory drugs Despite the efficacy of steroid therapy for DMO, the response to topical non-steroidal anti-inflammatory drugs (NSAIDs) has not been demonstrated in clinical trials [65]. The DRCR.net Protocol R study (ClinicalTrials.gov: NCT01331005) compared 0.1\% nepafenac with placebo and demonstrated no anatomical or visual benefit after 12 months of therapy for non-centreinvolving DMO [66].

An animal model has demonstrated the benefit of highdose systemic aspirin in the suppression of BRB breakdown, but the translational dose in humans of $50 \mathrm{mg} / \mathrm{kg}$ would result in severe side effects [67].

Switching from anti-VEGF to steroid Higher intravitreal levels of inflammatory cytokines are associated with more severe DMO, suggesting that inflammation may play a greater role in treatment-resistant disease [68]. Chronic DMO may also be more likely to be driven by inflammatory cytokines. In the long-term follow-up of the FAME study, eyes with DMO for longer than 3 years had superior visual outcomes to those with a shorter history [61]. Switching therapy from
anti-VEGF agents, which may be more efficacious earlier in the natural history of DMO, to steroid therapy follows this rationale.

Several studies have assessed the utility of a dexamethasone implant for DMO resistant to anti-VEGF therapy, as summarised in Table 1 . These are mostly retrospective case series or prospective cohort studies, most of which demonstrated both anatomical and visual improvement at the end of follow-up [69-77]. The only randomised controlled trial assessing dexamethasone for anti-VEGF-resistant DMO found an anatomical benefit in combination with bevacizumab, but demonstrated no change in BCVA at 12 months [73]. Switching therapy to intravitreal triamcinolone is also effective, but the duration of action is limited compared with dexamethasone implants [78, 79].

\section{Anti-VEGF therapy}

The identification of VEGF-A as a key growth factor in the pathogenesis of DMO has revolutionised the management and treatment outcomes of this condition. The VEGF molecule stimulates angiogenesis, increases the permeability of capillary endothelium and decreases inhibition of pro-apoptotic proteins [80]. It is released by glial cells (including Müller cells, astrocytes and ganglion cells) as well as endothelial and RPE cells in response to the hyperglycaemia-mediated mechanisms previously discussed [81]. Five members of the VEGF family have been identified in humans (VEGF-A, VEGF-B, VEGF-C, VEGF-D and PlGF), with VEGF-A being implicated in the pathogenesis of ocular angiogenic diseases [80]. This protein binds to and activates the tyrosine kinase receptors VEGF receptor (VEGFR)-1 and VEGFR-2. PlGF additionally may play a role in the development of diabetic retinopathy, being found in increasing concentrations in proportion to the degree of ischaemic retinopathy [82]. It also alters RPE permeability, opening tight junctions and leading to the accumulation of subretinal fluid and retinal oedema [83].

Treatment with anti-VEGF drugs has now become the standard of care in many cases of DMO. There are currently four drugs used as intravitreal injections which target the VEGF pathway directly, summarised in Table 2: pegaptanib (Macugen, Eyetech Pharmaceuticals, Cedar Knolls, NJ, USA), bevacizumab (Avastin, Genentech, San Francisco, CA, USA), ranibizumab (Lucentis, Genentech) and aflibercept (Eylea, Regeneron, Tarrytown, NY, USA).

Pegaptanib is a pegylated anti-VEGF aptamer that competitively binds the VEGF-A 165 isoform, which has been demonstrated to be a key promoter of BRB breakdown [84]. It was evaluated in a double-blind sham-controlled trial (ClinicalTrials.gov: NCT00605280), which found patients in the pegaptanib arm had a greater improvement in visual acuity 
Table 2 Summary of intravitreal anti-VEGF agents available for DMO

\begin{tabular}{|c|c|c|c|c|c|}
\hline Drug name & $\begin{array}{l}\text { Doses trialled } \\
\text { for DMO }(\mathrm{mg})\end{array}$ & Structure & Mechanism of action & $\begin{array}{l}\text { Molecular } \\
\text { size (kDa) }\end{array}$ & $\begin{array}{l}\text { Intravitreal } \\
\text { half-life (days) }\end{array}$ \\
\hline $\begin{array}{l}\text { Pegaptanib (Macugen, } \\
\text { EyeTech Pharmaceuticals) }\end{array}$ & 0.3 & Pegylated RNA aptamer & $\begin{array}{l}\text { Binds VEGF-165 isoform of } \\
\text { VEGF-A }\end{array}$ & 50 & 10 \\
\hline $\begin{array}{l}\text { Bevacizumab } \\
\text { (Avastin, Genentech) }\end{array}$ & $1.25,2.5$ & $\begin{array}{l}\text { Full-length monoclonal antibody } \\
\text { to VEGF-A }\end{array}$ & Binds all VEGF-A isoforms & 149 & $7.0^{\mathrm{a}}$ \\
\hline $\begin{array}{l}\text { Ranibizumab } \\
\quad \text { (Lucentis, Genentech) }\end{array}$ & $0.3,0.5,2.0$ & $\begin{array}{l}\text { Monoclonal antibody fragment } \\
\text { to VEGF-A }\end{array}$ & Binds all VEGF-A isoforms & 48 & $2.5^{\mathrm{a}}$ \\
\hline $\begin{array}{l}\text { Aflibercept } \\
\quad \text { (Eylea, Regeneron) }\end{array}$ & 2.0 & $\begin{array}{l}\text { Fusion protein of binding domains } \\
\text { of VEGFR-1 and }-2 \text {, contains } \\
\text { Fc portion }\end{array}$ & $\begin{array}{l}\text { Decoy receptor for all isoforms } \\
\text { of VEGF-A, VEGF-B } \\
\text { and PlGF }\end{array}$ & 115 & $3.6^{\mathrm{a}}$ \\
\hline
\end{tabular}

${ }^{\mathrm{a}}$ From rabbit animal model data [108]

and a reduced need for rescue focal/grid laser therapy at both 36 weeks and 2 years of follow-up [85]. It has not been evaluated in any other published trial comparing it head-tohead with other therapies.

Bevacizumab, a recombinant full-length humanised monoclonal antibody that binds to the receptor-binding site for all isoforms of VEGF-A, was initially used as systemic therapy for the treatment of malignancies. It is currently used 'off label' for DMO. The randomised controlled Bevacizumab Or Laser Therapy (BOLT) study (eudract.ema.europa.eu: 2007-000847-89) of 80 eyes showed bevacizumab to be more effective at improving visual and anatomical outcomes than macular focal/grid laser therapy [86]. The improvements in BCVA and reduction of CMT were maintained after 2 years of follow-up.

Ranibizumab is a recombinant humanised monoclonal antigen-binding fragment that neutralises all forms of VEGF-A. Ranibizumab Monotherapy or Combined with Laser versus Laser Monotherapy for Diabetic Macular Edema (RESTORE) (ClinicalTrials.gov: NCT00687804), a three-arm randomised trial, compared intravitreal ranibizumab with or without macular laser vs sham injections with macular laser. This study showed improvements in both visual and anatomical outcomes in both ranibizumab arms, with no additional benefit from laser therapy [87]. In addition to the Protocol I study described previously, RIDE/RISE (ClinicalTrials.gov: NCT00473330/NCT00473382) were two multicentre studies comparing $0.3 \mathrm{mg}$ and $0.5 \mathrm{mg}$ doses of intravitreal ranibizumab and sham injections with adjunctive focal/grid laser photocoagulation according to perprotocol-specified criteria. Over twice as many participants treated with ranibizumab gained more than 15 letters in visual acuity after 24 months of follow-up compared with the laserrescue group [88].

Aflibercept is a recombinant protein produced by the fusion of the second Ig domain of VEGFR-1 and the third Ig domain of VEGFR-2 with the constant Fc portion of the $\operatorname{IgG}_{1}$. It acts as a decoy receptor for all isoforms of VEGF-A, VEGF-B and PIGF [89]. The safety and efficacy of aflibercept in managing DMO has been investigated in the phase II DME And VEGF Trap-Eye INvestigation of Clinical Impact (DAVINCI) trial (ClinicalTrials.gov: NCT00789477), the phase III VISTA/VIVID studies (ClinicalTrials.gov: NCT01363440/NCT01331681) and DRCR.net Protocol T [7, 90, 91]. DAVINCI and VISTA/VIVID demonstrated superiority of aflibercept in reducing CMT and improving visual acuity compared with ETDRS-guided laser photocoagulation $[90,91]$.

Protocol T was a double-blind three-arm multicentre phase III randomised controlled trial that compared bevacizumab $1.25 \mathrm{mg}$, ranibizumab $0.3 \mathrm{mg}$ and aflibercept $2.0 \mathrm{mg}$ in 660 eyes with DMO [7]. There was no clinically meaningful difference among these three drugs in improving BCVA. However, a post-hoc analysis demonstrated a greater benefit with aflibercept in patients presenting with a poorer visual acuity (<69 ETDRS letters). Additionally, aflibercept and ranibizumab were both superior to bevacizumab in reducing mean CMT; however, the difference between aflibercept and ranibizumab was not significant.

Systemic side effects have been flagged as a potential complication of anti-VEGF therapy. In the RISE/RIDE study, there was an increase in the number of thromboembolic events and deaths in the $0.5 \mathrm{mg}$ group compared with the laser group. While this difference did not reach statistical significance, other studies have suggested an association between ranibizumab and non-ocular haemorrhage and potentially other cardiovascular events [7]. However, there is a lack of good-quality evidence that would enable effective comparison of agents and definitive conclusions about the systemic safety of these drugs to be drawn [92].

Switching between anti-VEGF agents Though all of these drugs block the action of VEGF, differences in size, structure, mechanism of action and half-lives result in different clinical effects, as demonstrated in Protocol T. Consequently, resistance to anti-VEGF drugs is not uncommon. These drugs may also be more effective earlier in the natural history of DMO. When the sham arm in RISE/RIDE was switched to 
ranibizumab after 24 months, the gains in vision were less than in those started on ranibizumab earlier [88].

Previous studies of treatment-resistant neovascular age-related macular degeneration (nAMD) have shown benefit in switching therapy from one anti-VEGF drug to another, prompting others to investigate this approach in DMO [93]. These studies, summarised in Table 1, are heterogeneous in their design, inclusion and exclusion criteria and follow-up, making comparison difficult. However, there seems to be a universal anatomical improvement after switching from bevacizumab to ranibizumab [94-96]. and there may be a benefit in switching from either of these drugs to aflibercept [97-99]. The benefits of switching most likely have to do with improved binding affinity with VEGF and blockade of PIGF with aflibercept [100].

Dose response Compared with $\mathrm{nAMD}$, the intravitreal concentration of VEGF in DMO may be higher, suggesting there may be a role for increased blockade of the VEGF pathway for treatment-resistant disease [101].

The Residual Edema Evaluation with Ranibizumab $0.5 \mathrm{mg}$ and $2.0 \mathrm{mg}$ Formulations for Diabetic Macular Edema (REEF) study (ClinicalTrials.gov: NCT01292798) examined the effects of $0.5 \mathrm{mg}$ and $2.0 \mathrm{mg}$ ranibizumab on visual and anatomical outcomes for patients with bevacizumab-resistant DMO [95]. All participants were started on a $0.5 \mathrm{mg}$ dose, which was increased to $2.0 \mathrm{mg}$ if there was residual DMO after 3 months. Overall, $76 \%$ of patients demonstrated anatomical improvement with $0.5 \mathrm{mg}$ ranibizumab. Of the remainder, who were switched to a $2.0 \mathrm{mg}$ dose, $50 \%$ demonstrated anatomical improvement. The Ranibizumab for Edema of the Macula in Diabetes: Protocol 3 With High Dose (READ-3) study (ClinicalTrials.gov: NCT01077401) randomised participants with DMO to receive either $0.5 \mathrm{mg}$ or $2.0 \mathrm{mg}$ of ranibizumab; 6 month results showed no benefit with the higher dose of therapy [102]. It is likely that the effects of higher doses of ranibizumab may be equivocal. Similarly, a head-to-head study of $1.25 \mathrm{mg}$ and $2.5 \mathrm{mg}$ doses of bevacizumab showed no difference in BCVA or CMT between the groups after 6 months of therapy [103].

\section{Combination therapy}

The combination of anti-VEGF agents and corticosteroids may be more effective in certain patients whose DMO is difficult to control with anti-VEGF agents alone. In a threearm randomised trial, bevacizumab was compared with combination bevacizumab/triamcinolone and macular laser photocoagulation. After 16 weeks of follow-up, combination therapy for these patients provided a longer period of BCVA and CMT improvement [104].
Several studies have explored the efficacy of combined laser and anti-VEGF therapy, with rescue laser therapy forming part of several key trials of anti-VEGF, including Protocol T [7]. Although some smaller prospective studies have shown reduced need for intravitreal injections with combined laser therapy, larger trials such as RESTORE showed no benefit with combination laser and ranibizumab [87, 105]. A three-arm trial compared intravitreal bevacizumab, macular laser photocoagulation and a combination of the two. There was a significant improvement in visual acuity and CMT reduction in both bevacizumab treatment arms at 1 month, but this was not maintained in the bevacizumab monotherapy arm at 3 and 6 months. This study was limited by having only a single treatment and a 6 month follow-up [105].

\section{Summary}

Incomplete response to treatment for DMO has been described since the ETDRS report number 1 in 1985. Focal/ grid macular laser therapy used in this study has limitations for treating DMO and may result in poorer visual outcomes through photoreceptor damage and other complications. OCT, ultra-widefield FA, new laser technology, vitrectomy and a range of pharmacotherapies are available as diagnostic and treatment tools for treating clinicians. Although corticosteroid and anti-VEGF drugs have been shown to be more effective than argon laser in clinical trials, suboptimal response continues to be observed in a subgroup of these patients. Resistance to pharmacotherapy may represent abnormalities in the vitreoretinal interface. Anti-VEGF resistance may represent a progression in the natural history of DMO, with inflammation or alternative growth factors or cytokines increasingly contributing to the pathophysiology over time. The dynamic nature of DMO means that treatment modalities may need to be individualised throughout the course of treatment. Efficacy for therapies must be balanced with their risks. Trials evaluating treatment-resistant DMO are heterogeneous in design, follow-up, eligibility criteria and intervention. Therefore, formulating recommendations becomes challenging given the scarcity of strong scientific data. Nevertheless, from the current studies reviewed in this paper, patients who are refractory to one treatment may benefit from switching to a different agent or a combination therapy. The role of surgical procedures such as vitrectomy in treating medically treatment-resistant DMO needs further exploration.

Duality of interest $\mathrm{AC}$ is a consultant for Novartis, Bayer and Alcon and has received research grant funding from Bayer. All other authors declare that there is no duality of interest associated with their contribution to this manuscript. 
Contribution statement $\mathrm{BB}$ completed the systematic literature search and drafted the manuscript. $\mathrm{MZ}, \mathrm{TH}$ and $\mathrm{AC}$ were responsible for reviewing, editing and modifying the manuscript critically for intellectual content. All authors approved the final version of the manuscript.

\section{References}

1. Liew G, Michaelides M, Bunce C (2014) A comparison of the causes of blindness certifications in England and Wales in working age adults (16-64 years), 1999-2000 with 2009-2010. BMJ Open 4, e004015

2. Yau JW, Rogers SL, Kawasaki R et al (2012) Global prevalence and major risk factors of diabetic retinopathy. Diabetes Care 35: 556-564

3. Gonder JR, Walker VM, Barbeau M et al (2014) Costs and quality of life in Diabetic Macular Edema: Canadian Burden of Diabetic Macular Edema Observational Study (C-REALITY). J Ophthalmol 2014:939315

4. Early Treatment Diabetic Retinopathy Study research group (1985) Photocoagulation for diabetic macular edema. Early treatment diabetic retinopathy study report number 1 . Arch Ophthalmol 103:1796-1806

5. Pierro L, Giatsidis SM, Mantovani E, Gagliardi M (2010) Macular thickness interoperator and intraoperator reproducibility in healthy eyes using 7 optical coherence tomography instruments. Am J Ophthalmol 150(199-204), e191

6. Bressler SB, Qin H, Beck RW et al (2012) Factors associated with changes in visual acuity and central subfield thickness at 1 year after treatment for diabetic macular edema with ranibizumab. Arch Ophthalmol 130:1153-1161

7. Diabetic Retinopathy Clinical Research Network, Wells JA, Glassman AR et al (2015) Aflibercept, bevacizumab, or ranibizumab for diabetic macular edema. N Engl J Med 372: 1193-1203

8. Klaassen I, Van Noorden CJ, Schlingemann RO (2013) Molecular basis of the inner blood-retinal barrier and its breakdown in diabetic macular edema and other pathological conditions. Prog Retin Eye Res 34:19-48

9. Dong N, Xu B, Chu L, Tang X (2015) Study of 27 aqueous humor cytokines in type 2 diabetic patients with or without Macular Edema. PloS One 10, e0125329

10. Funk M, Schmidinger G, Maar N et al (2010) Angiogenic and inflammatory markers in the intraocular fluid of eyes with diabetic macular edema and influence of therapy with bevacizumab. Retina 30:1412-1419

11. Cameron NE, Cotter MA (1997) Metabolic and vascular factors in the pathogenesis of diabetic neuropathy. Diabetes 46(Suppl 2): S31-S37

12. Das Evcimen N, King GL (2007) The role of protein kinase C activation and the vascular complications of diabetes. Pharmacol Res 55:498-510

13. Aiello LP, Bursell SE, Clermont A et al (1997) Vascular endothelial growth factor-induced retinal permeability is mediated by protein kinase $\mathrm{C}$ in vivo and suppressed by an orally effective betaisoform-selective inhibitor. Diabetes 46:1473-1480

14. Stitt AW, Moore JE, Sharkey JA et al (1998) Advanced glycation end products in vitreous: structural and functional implications for diabetic vitreopathy. Invest Ophthalmol Vis Sci 39:2517-2523

15. Goldin A, Beckman JA, Schmidt AM, Creager MA (2006) Advanced glycation end products: sparking the development of diabetic vascular injury. Circulation 114:597-605

16. Arjamaa O, Minn H (2012) Resistance, not tachyphylaxis or tolerance. Br J Ophthalmol 96:1153-1154
17. Bresnick GH (1983) Diabetic maculopathy. A critical review highlighting diffuse macular edema. Ophthalmology 90:13011317

18. Patel RD, Messner LV, Teitelbaum B, Michel KA, Hariprasad SM (2013) Characterization of ischemic index using ultra-widefield fluorescein angiography in patients with focal and diffuse recalcitrant diabetic macular edema. Am J Ophthalmol 155(1038-1044), e1032

19. Regatieri CV, Branchini L, Carmody J, Fujimoto JG, Duker JS (2012) Choroidal thickness in patients with diabetic retinopathy analyzed by spectral-domain optical coherence tomography. Retina 32:563-568

20. Virgili G, Menchini F, Casazza G et al (2015) Optical coherence tomography (OCT) for detection of macular oedema in patients with diabetic retinopathy. Cochrane Database Syst Rev 1, CD008081

21. Chung EJ, Roh MI, Kwon OW, Koh HJ (2008) Effects of macular ischemia on the outcome of intravitreal bevacizumab therapy for diabetic macular edema. Retina 28:957-963

22. de Carlo TE, Chin AT, Joseph T et al (2016) Distinguishing diabetic macular edema from capillary nonperfusion using optical coherence tomography angiography. Ophthalmic Surg Lasers Imaging Retin 47:108-114

23. Lopes de Faria JM, Jalkh AE, Trempe CL, McMeel JW (1999) Diabetic macular edema: risk factors and concomitants. Acta Ophthalmol Scand 77:170-175

24. Chew EY, Davis MD, Danis RP et al (2014) The effects of medical management on the progression of diabetic retinopathy in persons with type 2 diabetes: the Action to Control Cardiovascular Risk in Diabetes (ACCORD) Eye Study. Ophthalmology 121:2443-2451

25. Das R, Kerr R, Chakravarthy U, Hogg RE (2015) Dyslipidemia and Diabetic Macular Edema: a systematic review and meta-analysis. Ophthalmology 122:1820-1827

26. Li J, Wang JJ, Chen D et al (2009) Systemic administration of HMG-CoA reductase inhibitor protects the blood-retinal barrier and ameliorates retinal inflammation in type 2 diabetes. Exp Eye Res 89:71-78

27. Keech AC, Mitchell P, Summanen PA et al (2007) Effect of fenofibrate on the need for laser treatment for diabetic retinopathy (FIELD study): a randomised controlled trial. Lancet 370:16871697

28. ACCORD Study Group, ACCORD Eye Study Group, Chew EY et al (2010) Effects of medical therapies on retinopathy progression in type 2 diabetes. N Engl J Med 363:233-244

29. Wessel MM, Nair N, Aaker GD, Ehrlich JR, D'Amico DJ, Kiss S (2012) Peripheral retinal ischaemia, as evaluated by ultrawidefield fluorescein angiography, is associated with diabetic macular oedema. Br J Ophthalmol 96:694-698

30. Awata T, Kurihara S, Takata N et al (2005) Functional VEGF C-634G polymorphism is associated with development of diabetic macular edema and correlated with macular retinal thickness in type 2 diabetes. Biochem Biophys Res Commun 333:679-685

31. Churchill AJ, Carter JG, Ramsden C et al (2008) VEGF polymorphisms are associated with severity of diabetic retinopathy. Invest Ophthalmol Vis Sci 49:3611-3616

32. Abhary S, Hewitt AW, Burdon KP, Craig JE (2009) A systematic meta-analysis of genetic association studies for diabetic retinopathy. Diabetes 58:2137-2147

33. Lee CM, Olk RJ (1991) Modified grid laser photocoagulation for diffuse diabetic macular edema. Long-term visual results. Ophthalmology 98:1594-1602

34. Stefansson E (2006) Ocular oxygenation and the treatment of diabetic retinopathy. Surv Ophthalmol 51:364-380

35. Matsumoto M, Yoshimura N, Honda Y (1994) Increased production of transforming growth factor-beta 2 from cultured human 
retinal pigment epithelial cells by photocoagulation. Invest Ophthalmol Vis Sci 35:4245-4252

36. Lewis H, Schachat AP, Haimann MH et al (1990) Choroidal neovascularization after laser photocoagulation for diabetic macular edema. Ophthalmology 97:503-510

37. Diabetic Retinopathy Clinical Research Network, Elman MJ, Qin $\mathrm{H}$ et al (2012) Intravitreal ranibizumab for diabetic macular edema with prompt versus deferred laser treatment: three-year randomized trial results. Ophthalmology 119:2312-2318

38. Figueira J, Khan J, Nunes S et al (2009) Prospective randomised controlled trial comparing sub-threshold micropulse diode laser photocoagulation and conventional green laser for clinically significant diabetic macular oedema. Br J Ophthalmol 93:1341-1344

39. Harbour JW, Smiddy WE, Flynn HW Jr, Rubsamen PE (1996) Vitrectomy for diabetic macular edema associated with a thickened and taut posterior hyaloid membrane. Am J Ophthalmol 121: 405-413

40. Gaucher D, Tadayoni R, Erginay A, Haouchine B, Gaudric A, Massin P (2005) Optical coherence tomography assessment of the vitreoretinal relationship in diabetic macular edema. Am J Ophthalmol 139:807-813

41. Abrishami M, Moosavi MN, Shoeibi N, Hosseinpoor SS (2011) Intravitreal tissue plasminogen activator to treat refractory diabetic macular edema by induction of posterior vitreous detachment. Retina 31:2065-2070

42. Dillinger P, Mester U (2004) Vitrectomy with removal of the internal limiting membrane in chronic diabetic macular oedema. Graefe's Arch Clin Exp Ophthalmol 242:630-637

43. Quiram PA, Leverenz VR, Baker RM, Dang L, Giblin FJ, Trese MT (2007) Microplasmin-induced posterior vitreous detachment affects vitreous oxygen levels. Retina 27:1090-1096

44. Simunovic MP, Hunyor AP, Ho IV (2014) Vitrectomy for diabetic macular edema: a systematic review and meta-analysis. Can J Ophthalmol 49:188-195

45. Kakinoki M, Sawada O, Sawada T, Saishin Y, Kawamura H, Ohji M (2012) Effect of vitrectomy on aqueous VEGF concentration and pharmacokinetics of bevacizumab in macaque monkeys. Invest Ophthalmol Vis Sci 53:5877-5880

46. Mehta S, Blinder KJ, Shah GK, Kymes SM, Schlief SL, Grand MG (2010) Intravitreal bevacizumab for the treatment of refractory diabetic macular edema. Ophthalmic Surg Lasers Imaging 41: 323-329

47. Omri S, Behar-Cohen F, de Kozak Y et al (2011) Microglia/ macrophages migrate through retinal epithelium barrier by a transcellular route in diabetic retinopathy: role of $\mathrm{PKC} \zeta$ in the Goto Kakizaki rat model. Am J Pathol 179:942-953

48. Joussen AM, Murata T, Tsujikawa A, Kirchhof B, Bursell SE, Adamis AP (2001) Leukocyte-mediated endothelial cell injury and death in the diabetic retina. Am J Pathol 158:147-152

49. Miyamoto K, Khosrof S, Bursell SE et al (1999) Prevention of leukostasis and vascular leakage in streptozotocin-induced diabetic retinopathy via intercellular adhesion molecule-1 inhibition. Proc Natl Acad Sci U S A 96:10836-10841

50. Brooks HL Jr, Caballero S Jr, Newell CK et al (2004) Vitreous levels of vascular endothelial growth factor and stromal-derived factor 1 in patients with diabetic retinopathy and cystoid macular edema before and after intraocular injection of triamcinolone. Arch Ophthalmol 122:1801-1807

51. Felinski EA, Cox AE, Phillips BE, Antonetti DA (2008) Glucocorticoids induce transactivation of tight junction genes occludin and claudin-5 in retinal endothelial cells via a novel cis-element. Exp Eye Res 86:867-878

52. Gillies MC, McAllister IL, Zhu M et al (2011) Intravitreal triamcinolone prior to laser treatment of diabetic macular edema: 24month results of a randomized controlled trial. Ophthalmology 118:866-872
53. Chang AA, Li H, Broadhead GK, Luo K, Zhu M (2015) Safety and efficacy of intravitreal preservative-free triamcinolone acetonide (Triesence) for Macular edema. J Ocul Pharmacol Ther 31:563-569

54. Gillies MC, Simpson JM, Gaston C et al (2009) Five-year results of a randomized trial with open-label extension of triamcinolone acetonide for refractory diabetic macular edema. Ophthalmology 116:2182-2187

55. Ip MS, Bressler SB, Antoszyk AN et al (2008) A randomized trial comparing intravitreal triamcinolone and focal/grid photocoagulation for diabetic macular edema: baseline features. Retina 28:919930

56. Diabetic Retinopathy Clinical Research Network, Elman MJ, Aiello LP et al (2010) Randomized trial evaluating ranibizumab plus prompt or deferred laser or triamcinolone plus prompt laser for diabetic macular edema. Ophthalmology 117(1064-1077), e1035

57. Haller JA, Kuppermann BD, Blumenkranz MS et al (2010) Randomized controlled trial of an intravitreous dexamethasone drug delivery system in patients with diabetic macular edema. Arch Ophthalmol 128:289-296

58. Boyer DS, Yoon YH, Belfort R Jr et al (2014) Three-year, randomized, sham-controlled trial of dexamethasone intravitreal implant in patients with diabetic macular edema. Ophthalmology 121:1904-1914

59. Gillies MC, Lim LL, Campain A et al (2014) A randomized clinical trial of intravitreal bevacizumab versus intravitreal dexamethasone for diabetic macular edema: the BEVORDEX study. Ophthalmology 121:2473-2481

60. Pearson PA, Comstock TL, Ip M et al (2011) Fluocinolone acetonide intravitreal implant for diabetic macular edema: a 3year multicenter, randomized, controlled clinical trial. Ophthalmology 118:1580-1587

61. Campochiaro PA, Brown DM, Pearson A et al (2012) Sustained delivery fluocinolone acetonide vitreous inserts provide benefit for at least 3 years in patients with diabetic macular edema. Ophthalmology 119:2125-2132

62. Ornek K, Ornek N (2008) Intravitreal bevacizumab treatment for refractory diabetic macular edema. J Ocular Pharmacol Ther : Off J Assoc Ocul Pharmacol Ther 24:403-407

63. Yuksel E, Ozdek S, Yuksel N, Hasanreisoglu B (2013) Intravitreal bevacizumab treatment for refractory diabetic macular edema. Int Ophthalmol 33:659-663

64. Haritoglou C, Kook D, Neubauer A et al (2006) Intravitreal bevacizumab (Avastin) therapy for persistent diffuse diabetic macular edema. Retina 26:999-1005

65. Russo A, Costagliola C, Delcassi L et al (2013) Topical nonsteroidal anti-inflammatory drugs for macular edema. Mediat Inflamm 2013:476525

66. Friedman SM, Almukhtar TH, Baker CW et al (2015) Topical nepafenec in eyes with noncentral diabetic macular edema. Retina 35:944-956

67. Joussen AM, Poulaki V, Tsujikawa A et al (2002) Suppression of diabetic retinopathy with angiopoietin-1. Am J Pathol 160:16831693

68. Funatsu H, Noma H, Mimura T, Eguchi S, Hori S (2009) Association of vitreous inflammatory factors with diabetic macular edema. Ophthalmology 116:73-79

69. Bansal P, Gupta V, Gupta A, Dogra MR, Ram J (2015) Efficacy of Ozurdex implant in recalcitrant diabetic macular edema-a singlecenter experience. International Ophthalmology

70. Dutra Medeiros M, Postorino M, Navarro R, Garcia-Arumi J, Mateo C, Corcostegui B (2014) Dexamethasone intravitreal implant for treatment of patients with persistent diabetic macular edema. Int J Ophthalmol 231:141-146 
71. Escobar-Barranco JJ, Pina-Marin B, Fernandez-Bonet M (2015) Dexamethasone implants in patients with naive or refractory diffuse Diabetic Macular Edema. Ophthalmol J 233:176-185

72. Lazic R, Lukic M, Boras I et al (2014) Treatment of anti-vascular endothelial growth factor-resistant diabetic macular edema with dexamethasone intravitreal implant. Retina 34:719-724

73. Maturi RK, Bleau L, Saunders J, Mubasher M, Stewart MW (2015) A 12-month, single-masked, randomized controlled study of eyes with persistent diabetic macular edema after multiple antiVEGF injections to assess the efficacy of the dexamethasonedelayed delivery system as an adjunct to bevacizumab compared with continued bevacizumab monotherapy. Retina 35:1604-1614

74. Totan Y, Guler E, Guragac FB (2015) Dexamethasone intravitreal implant for chronic diabetic macular edema resistant to intravitreal bevacizumab treatment. Curr Eye Res 41:107-113

75. Gutierrez-Benitez L, Millan E, Arias L, Garcia P, Cobos E, Caminal M (2015) Dexamethasone intravitreal implants for diabetic macular edema refractory to ranibizumab monotherapy or combination therapy. Arch Soc Esp Oftalmol 90:475-480

76. Zhioua I, Semoun O, Lalloum F, Souied EH (2015) Intravitreal dexamethasone implant in patients with ranibizumab persistent diabetic macular edema. Retina 35:1429-1435

77. Alshahrani ST, Dolz-Marco R, Gallego-Pinazo R, Diaz-Llopis M, Arevalo JF, KKESH International Collaborative Retina Study Group (2016) Intravitreal dexamethasone implant for the treatment of refractory macular edema in retinal vascular diseases: results of the KKESH International Collaborative Retina Study Group. Retina 36:131-136

78. Jeon S, Lee WK (2014) Effect of intravitreal triamcinolone in diabetic macular edema unresponsive to intravitreal bevacizumab. Retina 34:1606-1611

79. Kim JH, Lee TG, Lew YJ (2015) Short-term efficacy of intravitreal triamcinolone acetonide for bevacizumab-resistant diabetic macular oedema. Acta Ophthalmol 93:e178-e179

80. Ferrara N, Gerber HP, LeCouter J (2003) The biology of VEGF and its receptors. Nat Med 9:669-676

81. Wang J, Xu X, Elliott MH, Zhu M, Le YZ (2010) Muller cellderived VEGF is essential for diabetes-induced retinal inflammation and vascular leakage. Diabetes 59:2297-2305

82. Kovacs K, Marra KV, Yu G et al (2015) Angiogenic and inflammatory vitreous biomarkers associated with increasing levels of Retinal Ischemia. Invest Ophthalmol Vis Sci 56:6523-6530

83. Miyamoto N, de Kozak Y, Jeanny JC et al (2007) Placental growth factor-1 and epithelial haemato-retinal barrier breakdown: potential implication in the pathogenesis of diabetic retinopathy. Diabetologia 50:461-470

84. Adamis AP, Berman AJ (2008) Immunological mechanisms in the pathogenesis of diabetic retinopathy. Semin Immunopathol 30: 65-84

85. Sultan MB, Zhou D, Loftus J, Dombi T, Ice KS, Macugen 1013 Study Group (2011) A phase 2/3, multicenter, randomized, double-masked, 2-year trial of pegaptanib sodium for the treatment of diabetic macular edema. Ophthalmology 118:1107-1118

86. Rajendram R, Fraser-Bell S, Kaines A et al (2012) A 2-year prospective randomized controlled trial of intravitreal bevacizumab or laser therapy (BOLT) in the management of diabetic macular edema: 24-month data: report 3. Arch Ophthalmol 130:972-979

87. Mitchell P, Bandello F, Schmidt-Erfurth U et al (2011) The RESTORE study: ranibizumab monotherapy or combined with laser versus laser monotherapy for diabetic macular edema. Ophthalmology 118:615-625

88. Brown DM, Nguyen QD, Marcus DM et al (2013) Long-term outcomes of ranibizumab therapy for diabetic macular edema: the 36-month results from two phase III trials: RISE and RIDE. Ophthalmology 120:2013-2022
89. Holash J, Davis S, Papadopoulos N et al (2002) VEGF-Trap: a VEGF blocker with potent antitumor effects. Proc Natl Acad Sci U S A 99:11393-11398

90. Do DV, Schmidt-Erfurth U, Gonzalez VH et al (2011) The DA VINCI Study: phase 2 primary results of VEGF Trap-Eye in patients with diabetic macular edema. Ophthalmology 118:1819-1826

91. Korobelnik JF, Do DV, Schmidt-Erfurth U et al (2014) Intravitreal aflibercept for diabetic macular edema. Ophthalmology 121: 2247-2254

92. Mitchell P (2011) A systematic review of the efficacy and safety outcomes of anti-VEGF agents used for treating neovascular agerelated macular degeneration: comparison of ranibizumab and bevacizumab. Curr Med Res Opin 27:1465-1475

93. Chang AA, Li H, Broadhead GK et al (2014) Intravitreal aflibercept for treatment-resistant neovascular age-related macular degeneration. Ophthalmology 121:188-192

94. Ciulla TA, Hussain RM, Ciulla LM, Sink B, Harris A (2015) Ranibizumab for diabetic macular edema refractory to multiple prior treatments. Retina. doi:10.1097/IAE.0000000000000876

95. Dhoot DS, Pieramici DJ, Nasir M et al (2015) Residual edema evaluation with ranibizumab $0.5 \mathrm{mg}$ and $2.0 \mathrm{mg}$ formulations for diabetic macular edema (REEF study). Eye 29:534-541

96. Hanhart J, Chowers I (2015) Evaluation of the response to ranibizumab therapy following bevacizumab treatment failure in eyes with diabetic macular edema. Case Rep Ophthalmol 6:44-50

97. Lim LS, Ng WY, Mathur R et al (2015) Conversion to aflibercept for diabetic macular edema unresponsive to ranibizumab or bevacizumab. Clin Ophthalmol 9:1715-1718

98. Wood EH, Karth PA, Moshfeghi DM, Leng T (2015) Short-term outcomes of aflibercept therapy for diabetic macular edema in patients with incomplete response to ranibizumab and/or bevacizumab. Ophthalmic Surg Lasers Imaging Retin 46:950-954

99. Rahimy E, Shahlaee A, Khan MA, et al (2015) Conversion to aflibercept after prior anti-VEGF therapy for persistent diabetic macular edema. Am J Ophthalmol 164:118-127

100. Papadopoulos N, Martin J, Ruan Q et al (2012) Binding and neutralization of vascular endothelial growth factor (VEGF) and related ligands by VEGF Trap, ranibizumab and bevacizumab. Angiogenesis 15:171-185

101. Pfister M, Koch FH, Cinatl J et al (2013) Cytokine determination from vitreous samples in retinal vascular diseases]. Der Ophthalmologe : Zeitschrift der Deutschen Ophthalmologischen. Gesellschaft 110:746-754 [article in German]

102. Do DV, Sepah YJ, Boyer D et al (2015) Month-6 primary outcomes of the READ-3 study (Ranibizumab for Edema of the mAcula in Diabetes-Protocol 3 with high dose). Eye 29:1538-1544

103. Lam DS, Lai TY, Lee VY et al (2009) Efficacy of 1.25 MG versus 2.5 MG intravitreal bevacizumab for diabetic macular edema: sixmonth results of a randomized controlled trial. Retina 29:292-299

104. Faghihi H, Roohipoor R, Mohammadi SF et al (2008) Intravitreal bevacizumab versus combined bevacizumab-triamcinolone versus macular laser photocoagulation in diabetic macular edema. Eur J Ophthalmol 18:941-948

105. Solaiman KA, Diab MM, Abo-Elenin M (2010) Intravitreal bevacizumab and/or macular photocoagulation as a primary treatment for diffuse diabetic macular edema. Retina 30:1638-1645

106. Kim YT, Kang SW, Kim SJ, Kim SM, Chung SE (2012) Combination of vitrectomy, IVTA, and laser photocoagulation for diabetic macular edema unresponsive to prior treatments; 3 year results. Graefe's Arch Clin Exp Ophthalmol 250:679-684

107. Yolcu U, Sobaci G (2015) The effect of combined treatment of bevacizumab and triamcinolone for diabetic macular edema refractory to previous intravitreal mono-injections. Int Ophthalmol 35:73-79

108. Park SJ, Oh J, Kim YK et al (2015) Intraocular pharmacokinetics of intravitreal vascular endothelial growth factor-Trap in a rabbit model. Eye 29:561-568 